\title{
The Maps That Killed Alexander Posey
}

\author{
Matt Cohen
}

\begin{abstract}
Nineteenth-century struggles over mapping concepts and techniques yielded the forebears of digital humanistic data visualizations today, staging the political tensions of the deep map's entry into the humanities. The careers of educational reformer Emma Hart Willard and Creek poet and critic Alexander Posey, who were both map-makers in their ways, exemplify the entanglements of the history of deep mapping. Willard was a feminist innovator in her work with historical visualization, but at the cost of solidifying a regime of indigenous vanishment. Posey fought for his people's cultural survival, but he did so from within a bureaucratic engine made possible in part by Willard's widespread pedagogy linking the American map with a vision of settler dominance. These two figures left us provocative maps, but also offer a way to reflect on the justness of map-making — on the difficulty of deepening the map wisely, or even ethically.
\end{abstract}

Roll on, ye Prairies of the West,

Roll on, like unsailed seas aways!

I love thy silences

And thy mysterious room.

- Alexander Posey, "Prairies of the West"1

\begin{abstract}
Alexander Posey didn't die in particularly deep water when he was swept away by the swollen Oktahutche river on May 27, 1908. The famous Muscogee Creek writer, editor, and educator had a lifelong fear of drowning. Perhaps that fear shaped one of his poetic depictions of a beneficent landscape saving humans from the dangers of the current:
\end{abstract}

1. Posey 2008, 87. For the first publication of Posey's poems, see Posey 1910. 
Why do trees along the river

Lean so far out o'er the tide?

Very wise men tell me why, but

I am never satisfied;

And so I keep my fancy still,

That trees lean out to save

The drowning from the clutches of

The cold, remorseless wave.

$(2008,74)$

From one perspective, it was a river he loved, an axis of Creek culture in Indian Territory and Oklahoma that he wrote into poetry and prose, that took his life. From another, we might say it was two deep maps that killed Alexander Posey.

This essay indicates the parallel enthusiasms in the humanities today for new visualization technologies and for new ways of telling scholarly stories. "Deep mapping", in its digital instantiation, is one of a number of transmedia experimental methods that leverage the maturity of electronic techniques for transforming complex humanities information into machine-readable layers - GIS, force vector graphs, topic modeling, immersive environments, dynamic or crowdsourced digital archives. Born of writers and artists who felt an ecocritical, reparative urge, the deep map can be textual, visual, digital, physical, virtual, in situ, portable - a freeing of format, medium, and apparent accessibility that is exhilarating to many scholars. Given recent rapid advances in markup technology, algorithm development, and interface design, it appears possible to introduce into digital knowledge representations the kind of ambiguity and fuzziness on which the humanities thrive. All this seems to warrant experimentation, innovation, and exploration with deep mapping as a humanities framework. ${ }^{2}$

Yet those three terms - experimentation, innovation, and exploration - are keywords of Western colonialism. If we are to test the promises of the deep map against history, the place of mapping in the settlement of North America and the dispossession of its Native people is a good place to

2. John Corrigan defines a deep map as a spatial narrative; for an overview, see Bodenhamer, Corrigan, and Harris, eds. 2015. See also Ridge, LaFreNiere, and Nesbit, 2013, 176-89; and on the larger context of the transformation of cartographic philosophy and technique, see Kitchin, Perkins, and Dodge 2009, 1-25. 
start. The deep map concept's deprivileging of Cartesian cartographicism in favor of experientialism and multiplicity can distract us from the processual dimensions of mapping (or the generation of any other kind of cultural representation) and their ethics. "The history of the mistranslation and misrepresentation of Indigenous cartographies into Western cartographies virtually defines the history of Western colonization and coercion of Indigenous peoples", argue Margaret Pearce and Renee Paulani Louis $(2008,110) .{ }^{3}$ Consider that cartography has since the 1970 s been increasingly used by Indigenous people to defend their political and economic self-determination, and the application of digital technologies plays a key role in these efforts to maintain both cultural heritage and political selfdetermination. ${ }^{4}$

Pearce and Louis call for a creative, multicultural use of cartographic language (a metaphor for the processes and representational techniques of mapping) "as a potentially useful means of incorporating Indigenous and non-Indigenous conventions in the same map" (2008, 107). Even then, as Matthew Sparke has argued, Western cartography, interwoven with regimes of authority as it is, can both give and take away, from an Indigenous perspective: if judges or courts refuse to recognize its competing representational ontology, a map's respect for Native processes or cosmology won't accomplish the end of protecting legal sovereignty. ${ }^{5}$ This link to authoritative regimes of power, whether in the courtroom or the academy, entails an attention to methodology and ethics in scholarly discussions of deep mapping outside the professional realm of cartography.

Here, I offer a look at deep mapping neither in a celebratory nor a tragic mode, but in the elegiac mood. The story that follows, I argue, is part of the history of digital humanities. I tell it not to dismiss or celebrate the advent

3. For further contextualization, see PeArce and Louis 2008, 107-26.

4. Ethnohistorical scholarship on Indigenous American mapping suggests that resistant cartography has been employed since at least the era of Columbus; see for example Mundy 1996; and Lewis 1998. For a range of approaches to digital representations of Indigenous space, see for example, The Ways (https:/theways.org/); the Penobscot Nation's map site (https:/www.penobscotnation.org/ departments/natural-resources/gis-mapping/maps-for-download); Ritterbush, ET AL., https://tourbuilder.withgoogle.com/builder\#play/ahJzfmd3ZWItdG91cmJ1aWxkZXJyEQsSBFRvdXIYgICAoM78_QgM; and the ongoing Indigenous Mapping Workshop, http://imwcanada2015.earthoutreach.org. See also Basso 1996; Rundstrom 1991, 1-12; Rundstrom 1998, 1-9; and Chapin, Threlkeld, and Center for the Support of Native Lands 2001.

5. See Sparke 1998, 463-95. 
of new visualization opportunities, but to stage the ethical tensions of the deep map's entry into the digital humanistic scene. Inquiry into the history of mapping's practice and a genealogy of ethical concerns have to be taken up as we think about deep mapping projects going forward. In looking at the history of deep mapping and its entanglements, I turn to Emma Hart Willard and Alexander Posey, who were both map-makers, in their ways, in America's long nineteenth century. Willard was a feminist innovator in her work with historical visualization and pedagogy, but at the cost of solidifying a regime of indigenous vanishment. Posey fought for his people's cultural survival, but he did so from within the bureaucratic engine made possible in part by Willard's widespread pedagogy linking the American map with a grand settler colonial vision of dominance. These two figures have left us maps of different kinds, but they also give us more: a way to reflect on the justness of map-making, on the difficulty of deepening the map wisely, or even ethically.

The first map that killed Posey was the universal history map. Long before Jared Diamond's Guns, Germs, and Steel or Yuval Noah Harare's bestseller Sapiens came the nineteenth-century's epic universal histories of the human race. Emma Willard's works exemplify the excitement over the potential of what was then a new form of visualization. Willard was an activist and educator, founder of the Troy Female Seminary in New York, and creator of textbooks and atlases of wide and enduring popularity. One of her early American history books opens with an engraving of the conceptual "American Temple of Time", a foreshortened version of her data visualization of the broader human "Temple of Time" (see figs. 1 and 2).

Lining the floor of the temple is a visually compelling diagram, deep with respect both to chronology and historical nuance. Ribbons - or better, streams - of cultural, political, economic, and military power flow across each other and strikingly minimize the overall importance of the United States (see fig. 3).

But there are no indigenous Americans represented here, no aboriginal civilizations that count, only a vaguely hinted-at darkness, a shadowy uncivilization that undergirds all of time back to "Creation" in 4004 B.C.E.,

6. See Willard 1866; see also Willard 1829 and Willard 1845. Susan Schulten $(2007,542-64)$ argues that the ribbons of civilizational development image can be traced back to the designs of William Playfair, the eighteenth-century English data visualizer. 


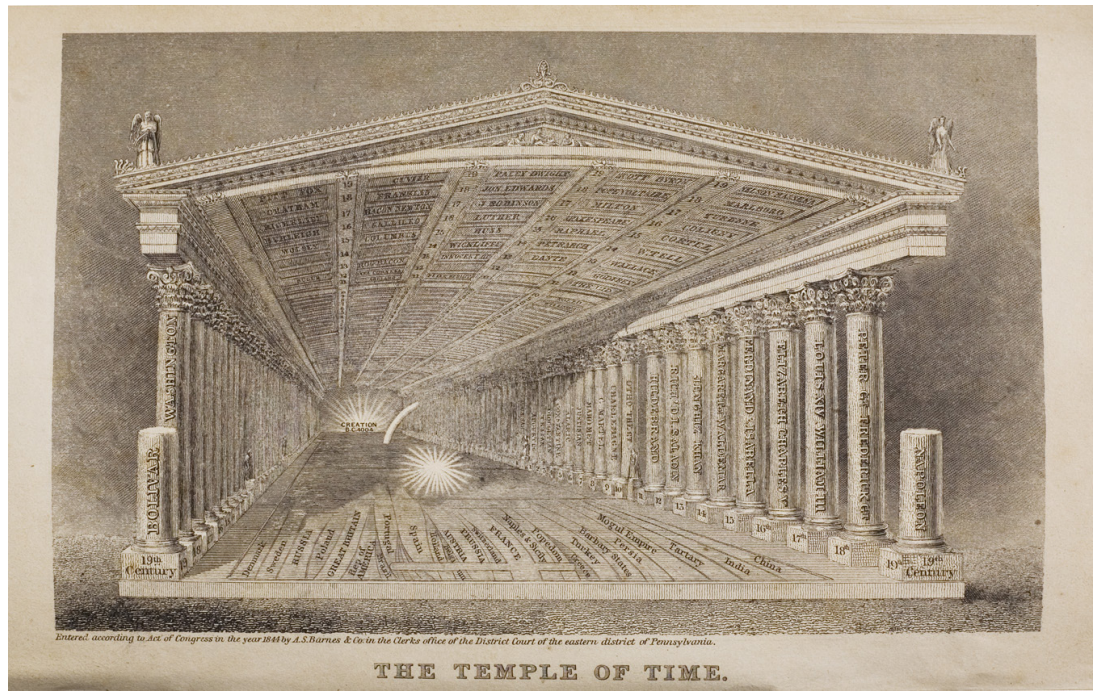

Figure 1. The history of civilization, represented as "The Temple of Time", a Christian temporal map housed in classical architecture. From Emma Willard, Universal History in Perspective (New York: A.S. Barnes, 1845).

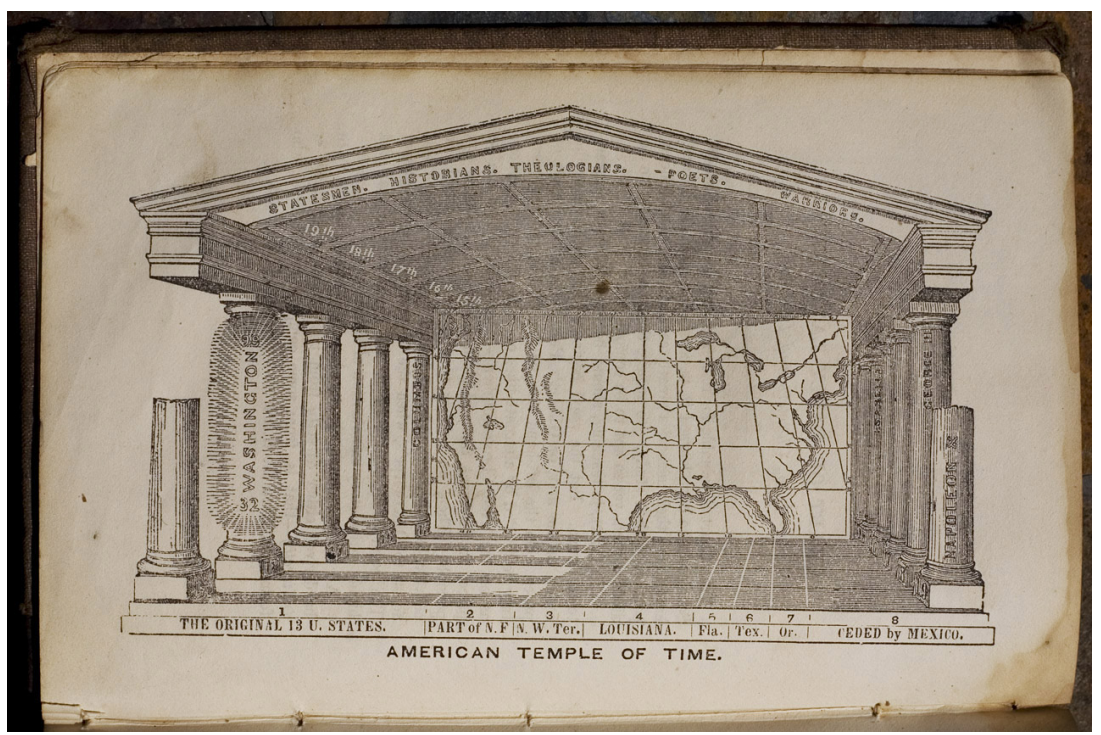

Figure 2. The incomplete Unites States map and "American Temple of Time". From Emma Willard, Abridged History of the United States, or Republic of America, new and enlarged (New York: A.S. Barnes, 1866). 


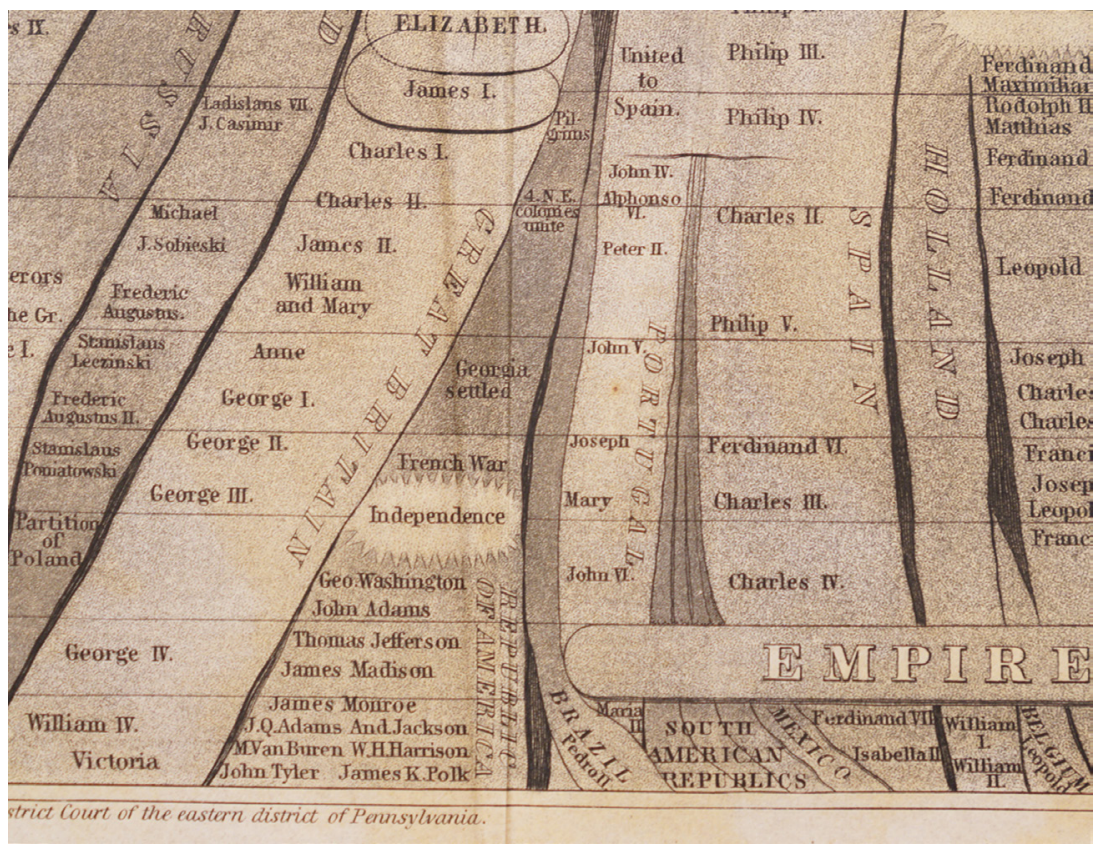

Figure 3. The minor advent of the United States, and the murky background shades of indigeneity. Detail of "Perspective Sketch of the Course of Empire", from Willard, Universal History in Perspective.

Figure 4. The chaotic landscape of Indigenous America in Map No. 1, from Willard, Abridged History of the United States.

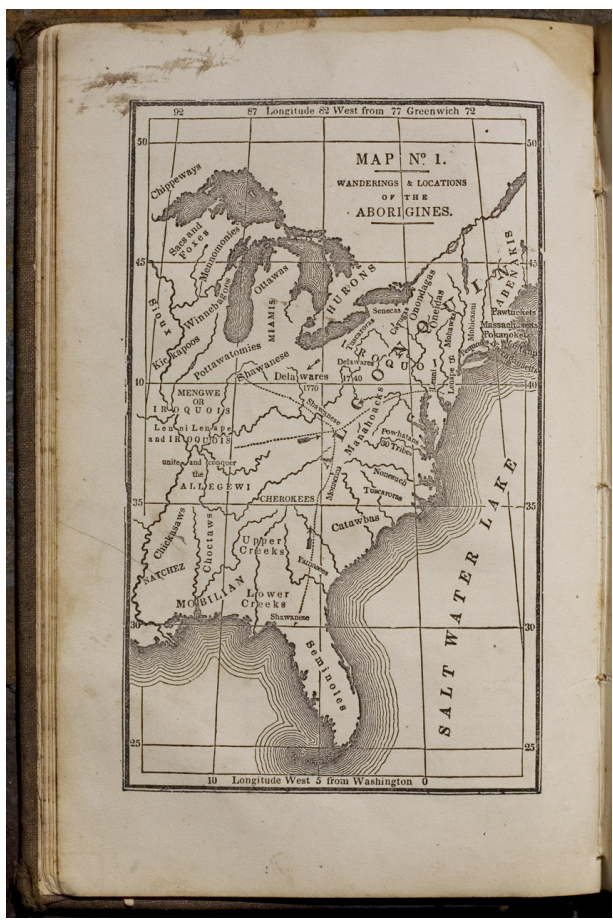


a beginning to which no indigenes appear to trace their origins. Indeed, this history of the United States, which helped bring Willard's work to national significance, contains but two short and inaccurate chapters about American Indians and a map of the "Locations and Wanderings of the Aborigines". Susan Schulten $(2012,25)$ observes that Willard's loose, "introductory" map of Indigenous nations places them, stereotypically, in a "timeless space prior to human history"? Willard's visualized streams of time were cold, remorseless waves, Posey might say.

Willard's many maps and chronometric visualizations shared ideological assumptions with other universal histories of the time. China, we are told in Israel Smith Clare's 1878 Illustrated Universal History, "is supposed to have been founded by Noah soon after the dispersion of mankind from the Tower of Babel" (22), neatly folding it into the Christian origin story. "She 'mapped' history", Schulten writes of Willard, "in order to create a national past that would translate the fact of the country as a territorial entity into the much more powerful idea of the country as a nation" (2012, 543). Inscribed here is a national past, to be sure: but the "American Temple of Time" emerges from a deeper and broader context of racial discourses of civilization underwriting indigenous dispossession and genocide across the world. Its design equates a certain understanding of deep time with the spread of a certain kind of empire - Christian, Western, "civilized". ${ }^{8}$

Willard's images are undeniably striking. To many readers, then and now, they have offered memorable experiments in the representation of deep human space and time. Lauren Klein, among a number of scholars working on feminist visualization techniques, has recently argued for a humanistic attention to data visualization and its histories as a way not only to move beyond narrative modes of making knowledge but also of calling attention to the "process of scholarly research". She advocates for humanistic experiments with data visualization that "present concepts, advance arguments, and perform critique". ${ }^{9}$ Certainly Emma Willard's visualizations were doing

7. See also the striking contemporaneous frontispiece illustration to S. Augustus Mitchell, A System of Modern Geometry (Philadelphia: Thomas, Cowperthwait, 1845), depicting the "Stages of Society" from "Barbarous" and "Savage" to "Civilized and enlightened". I am grateful to Abram Van Engen for sharing with me his forthcoming research on Willard and the institutionalization of American nationalism.

8. For reviews of Willard's American history and an account of her defense against "trespasses on my literary property", see WiLlaRD 1847.

9. The passages from Klein cited above are from her (unpublished) 2014 public lecture "Feminist Data Visualization" given at the HUMlab, Umeá University, 
those things, and Klein's attention to the feminist dimensions of these images is important.

An extension of feminist visualization, however, might attend to the way in which interactive frameworks have been enabled by hierarchical and teleological dynamics peculiar to settler colonialism. Willard's visualizations invite students to interact with them, as part of a larger strategy in her textbooks, involving interrogation, dialogue, and a sort of fill-in-theblank approach in which history is something unfinished, as you can see in the frontmost pillars of the temple of time. "This sketch", the description of the "American Temple of Time" says, "may be enlarged and filled up by the pupil, by a drawing of his own" (WILlard 1866, xiii). Willard also adapted past timeline-rendering techniques, which were often angular, to introduce a sense of the receding sharpness of history, the atmospheric quality of the distant past, the fluid, bending shape of a historical tributary. But while Willard's methods destabilize binaries, the boundaries between the western subject and history as authoritative narrative, they do so by maintaining other binaries, particularly the concepts of civilization, nation, and race. Willard's plan for female education was profoundly nationalist and explicitly expansionist. Her progressive claim about female education was rooted in the insistence that the course of history "points to a nation, which, having thrown off the shackles of authority and precedent [. . .] would rather lead than follow, in the march of human improvement", bringing that "race of men [. . . unparalleled glory" $(1919,25) .{ }^{10}$ History is unfinished, Willard's oeuvre suggests, but you may be sure it will not be finished by Indigenous people.

This would perhaps have been enough to kill a man, but Alexander Posey was subject to another map as well. He was born in 1873 at Tuskegee Cana-

Sweden. In the same lecture, Klein, speaking of nineteenth-century data visualizers like Willard, her sister Almira Phelps, and Elizabeth Palmer Peabody, observed, "As women they were more attendant to the contingent position of the viewer of the visualization because it mirrored their own contingent status in that culture"; Klein further suggested that these women's work hints at an important theoretical understanding of the relations between data and interface: that "it is through the visual form selected or created by the designer that the underlying data is reshaped" to the point that "at times the data's initial meaning or significance is overturned altogether". See also Joyce $(2015,80)$, who refers to the "Temple of Time" as "a conceptual masterpiece".

10. On Willard's life and fame, see Lutz 1929. 
dian, on the Canadian River, the town where Posey's family had settled after the Civil War. His family hailed from both Confederates and Union sympathizers, but largely on the Creek side (his mother's) from White Town and Wind Clan people who were known as peacemakers and political mediators. The contemporary Mvskoke /Creek poet Joy Harjo conveys a sense of the Wind Clan's role with a line in her poem "Once the World Was Perfect". Having lost the originary perfect world, the poem's speaker says, "We were bumping into each other / In the dark":

Then one of the stumbling ones took pity on another

And shared a blanket.

A spark of kindness made a light.

The light made an opening in the darkness.

Everyone worked together to make a ladder.

A Wind Clan person climbed out first into the next world. ...

(Harjo 2015, 14)

First into the next world. Posey graduated from Bacone Indian University in Muskogee, and served as a school superintendent, politician, and newspaper editor. Across his work, he laid explicit claim to his role as an indigenous intellectual, drawing on Creek oral traditions and ways even as he advocated for the pragmatic adoption of the regimes of the United States. He is most famous as the writer of the satirical "Fus Fixico Letters". ${ }^{11}$ But he is also notorious as an agent of the Dawes Commission, involved in shady land deals as a functionary of the U.S.'s attempt to "allot" (privatize) Indigenous land, fracture American Indian communities, and strengthen U.S. sovereignty. Given allotment's strategy of removing collective ownership and establishing single-tribe lineages, it might seem Posey was riding the remorseless wave, not surrendering to it.

Certainly, Posey had been no stranger to Western-style spatial entrepreneurship. When a neighbor laid claim to a piece of land he had previously staked out, Posey staked off an even larger area around the culprit, isolating him. "I pay Boone back in his own coin", he said, "and in some of my own."12 The logic that underlays Willard's depictions of civilization's progressive flow appealed to him, seemed to present an inevitability to which American Indians must adapt. Posey's first job with the Dawes Commission was as an interpreter, starting in 1904 . He was quickly appointed clerk of a

11. See Posey 1993.

12. Posey quoted in Littlefield 1992, 99. 
field party, charged with getting as many Creeks on the allotment rolls as possible. The work involved over eighteen months of extensive and sometimes difficult travel across the entire Creek territory, including parts of other nations' territory in which Creeks were rumored to be living. Still more difficult was navigating the intense resistance from those who disagreed with the policy of privatization. One of Posey's news reports in the Indian Journal chronicled the opposition of Wacache, one of the Creek traditionalists termed "Snakes" during the allotment period. Daniel Littlefield describes dramatically how Wacache, a well-off farmer,

refused to enroll for an allotment, and when the land his home sat on was selected by someone else, he burned his house piece by piece, along with most of his possessions. He kept a fire burning there constantly, held dances, became a 'prophet,' and acquired a great following among not only the Creek Snakes but those of the Choctaw Nation as well, whom Alex labeled "ignorant" and "credulous".

Posey's progressivist judgments notwithstanding, his documentation of the forms and acts of resistance by the Snakes both in his journalism and in his reports for the Dawes Commission (figs. 5 and 6) stands side-by-side with his bureaucratic acts of property management on behalf of settler colonialism. 


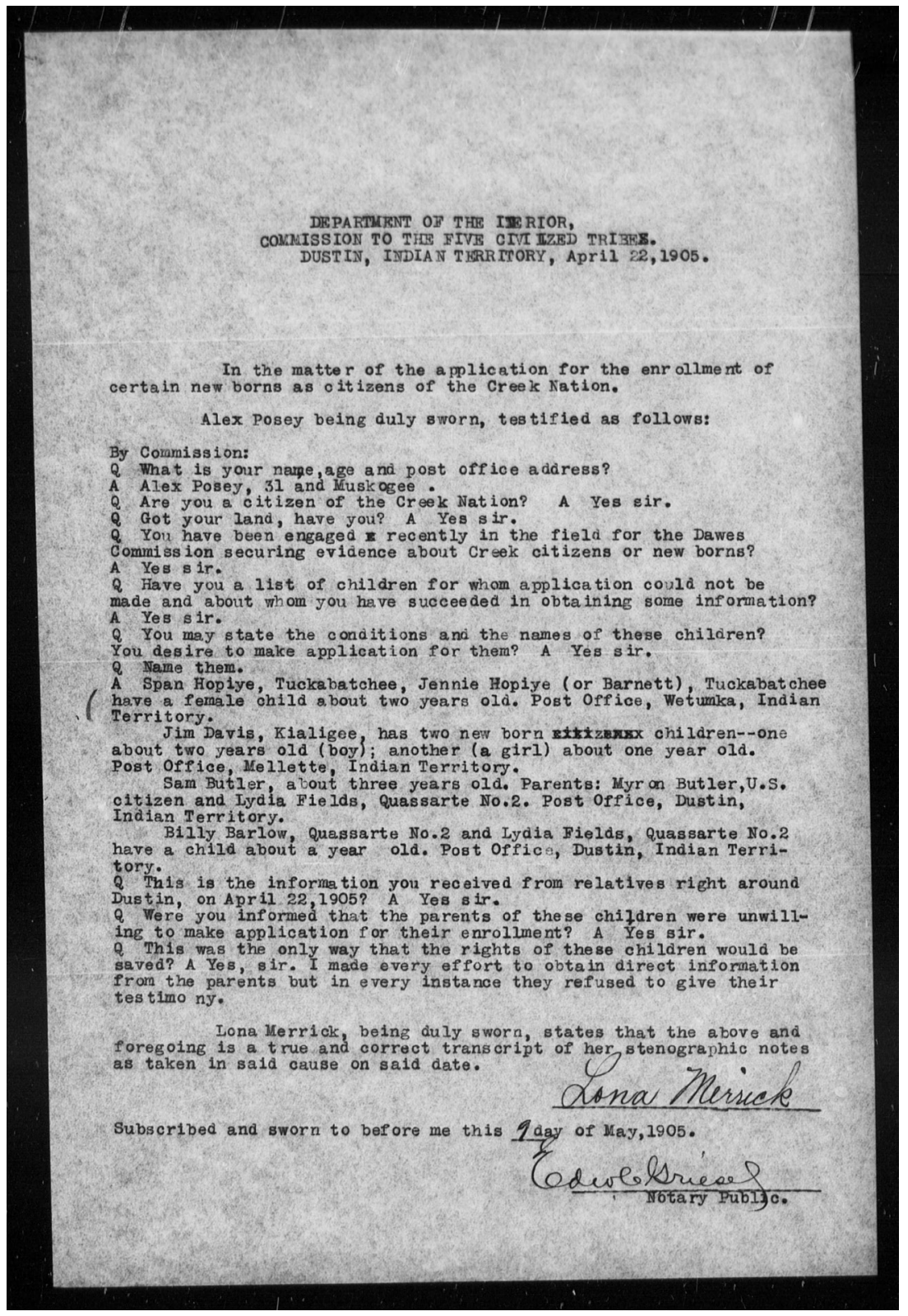

Figure 5. Alex Posey testifies on behalf of Creek "Snake" children, for the Dawes Commission. Dawes Enrollment Jacket for Creek Newborn, Card \#981, National Archives Identifier 45183630. https://catalog.archives.gov/search?q=Alex\%Posey\&f. ancestorNaIds $=617283 \&$ offset $=20$. 


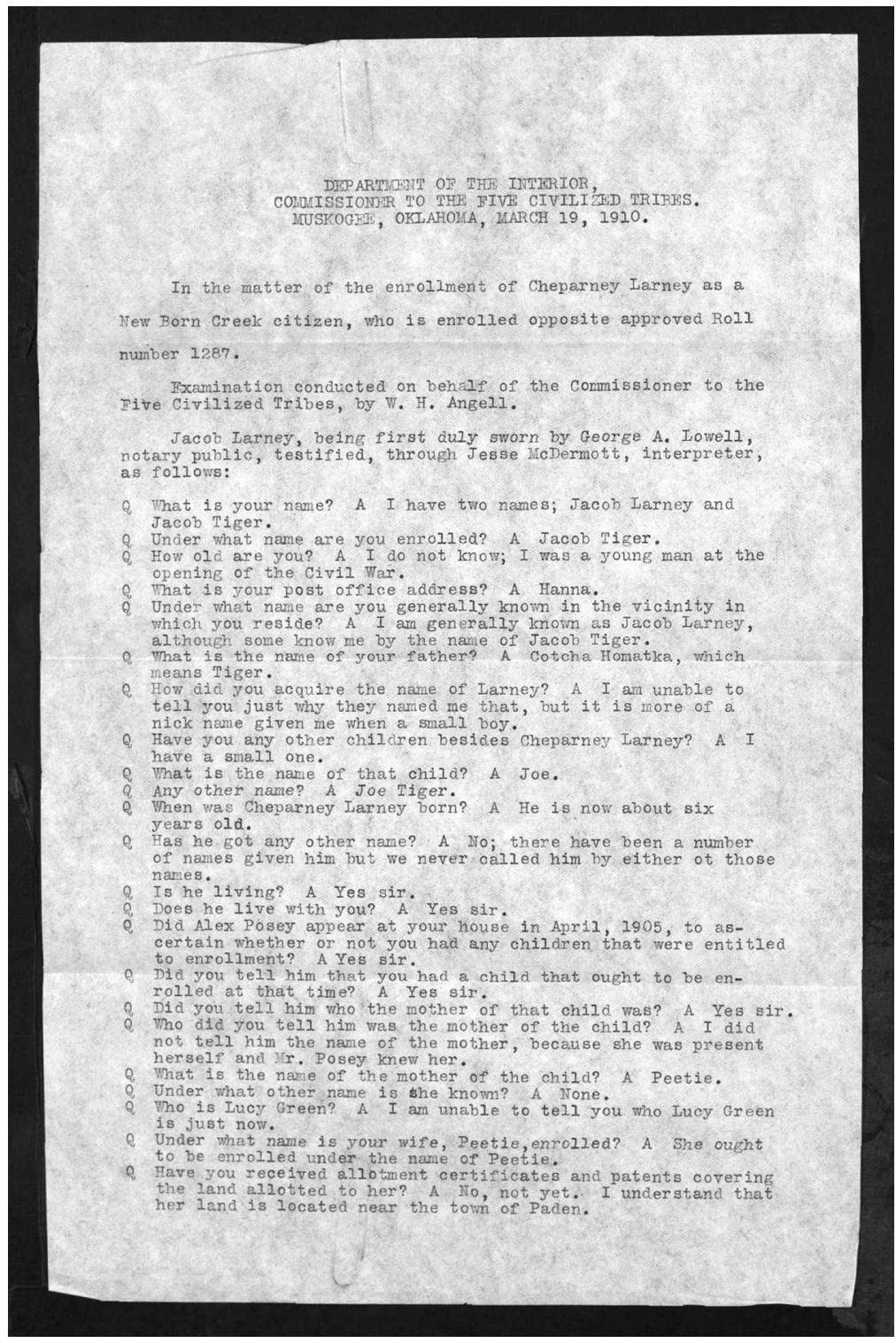

Figure 6. An account of one of Posey's visits to a Creek family during allotment. "Oklahoma Applications for Allotment, Five Civilized Tribes, 1899-1907”, National Archives and Records Administration, Southwest Region, Fort Worth, Texas. Database with images available atFamilySearch; https://familysearch.org/ark:/61903/3:1:S3HY-61CSCBT?cc $=1390101 \& w c=$ MXHG-G29\%3A967440501\%2C 967463101 . 
This deep map captures acts of mutual justification that destabilize the cartography, archives, and histories of both the United States and the Creek Nation. ${ }^{13}$ Posey was making, or extending, a deep map of Creek territory and culture with his stories, collections of Creek objects, poetry, and journalism. He was doing so by way of, rather than in contradistinction to, his work verifying the brutal appropriative maps of the Dawes Commission (fig. 7).

"Alex Posey has sung the beauty and glory of his Indian country in verse that will live as long as the name of Oklahoma shall endure on her monuments", his journalism colleagues wrote upon his passing. "He has woven the names of the rivers, mountains, valleys and plains into song and story which will inspire the young patriots of other generations and brighten the pages of the nation's literature."14 And so Posey's fame was depicted as dependent upon the same project that launched Emma Willard's mapping career. Yet the immersive environment that killed Posey — a river he dearly loved, apostrophized in poem after poem - was part of another, fatal map, derived from the spiritual cosmography of the Creek people. "As the red men say", his Creek friend Charles Gibson said, "it was in the beginning ordained that he should retire from this life as he did." 15 The land grabs and allocation that Posey got caught up in were products of an understanding of space that Willard's maps gave a kind of cosmological warrant. But a Creek deep map - the haunting prescience of drowning in the river, the spirits sending a message to Creeks who would sell off space, Posey's own commitment to compromise, to being first into the next world, rooted in his Wind Clan and White Town origins - this deeper map, some Creeks still claim, took his life. ${ }^{16}$ Even in the absence of his allotment dealings, they might still be saying the same.

Posey never made it into major anthologies of American poetry, but Emma Willard did. "Rocked in the Cradle of the Deep" appears in Edmund Clarence Stedman's American Anthology and was widely loved. It defies the terrors of drowning that haunted Posey's verse:

13. For more on Posey's work with the Dawes Commission, the Snakes, and the "lost Creeks", see Lit TLEFIELD i 992, especially chapter 8.

14. Indian Journal, 5 June 1908; quoted in Litt Lefield 1992, 258.

15. Gibson quoted in Litt Lefield 1992, 251.

16. See discussions of Posey's reputation among Creeks in Littrefield 1992 and WомАск 1999. 


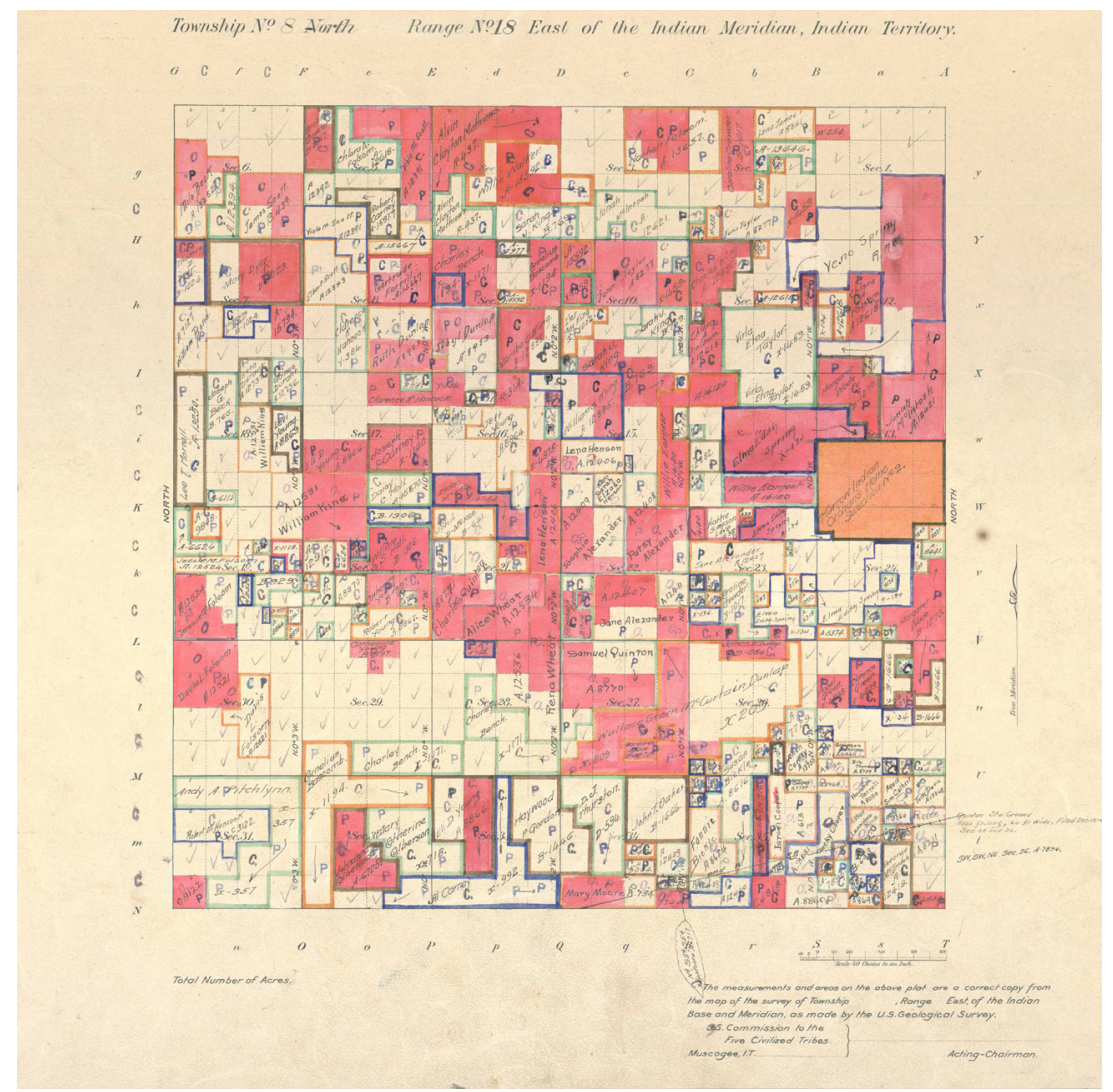

Figure 7. Allotment Map of Township 8 North of Range 18, East of the Indian Meridian, in Indian Territory. National Archives Identifier 652462. Records of the Bureau of Indian Affairs, 1793-1999; records group 75. https://catalog. archives.gov/search?q=*:*\&f.parentNaId=652462\&f.level=item\& sort=naIdSort $\% 20$ asc\&offset $=380$.

When in the dead of night I lie And gaze upon the trackless sky, The star-bespangled heavenly scroll, The boundless waters as they roll, I feel thy wondrous power to save From perils of the stormy wave: Rocked in the cradle of the deep, I calmly rest and soundly sleep. (Stedman 1900, 29.) 
The trackless sky, the boundless waters: the imagery is anti-cartographical, but the map is still there, underlying berth and rhyme. The sublime power of God to sink her ship is counteracted by the assurance of immortality. The depths she had labeled — briefly playing Indian — as the "Salt Water Lake" in her map of the "Locations and Wanderings of the Aborigines" did not take Emma Willard.

Posey and Willard stand both together in a genealogy of colonialist mapping and in juxtaposition - despite each in a sense having started from the cultural margins - as two figures affected in different ways by that genealogy. If data visualization is as much or more about method than about content, then the premises and preclusions of the universal map as an archetype are hazardous, for it is not merely a matter of inclusion at the level of the dataset, but something more social, more ontological, that must be addressed. Of course, we know that maps are dangerous for Indigenous people, for the dispossessed. But this does not preclude considering the seemingly utopian aspect of deep mapping, its appeal to nuance and complexity, to an appreciation of the past and diversity, and the degree to which that too may be wrapped up in the history of colonization. In taking seriously the metaphor of depth in the term deep mapping, I suggest that the deep history of deep mapping across epistemologies ought to be a starting point for us. And an entailment of moving across epistemologies, is that we maintain a real sense of the conflicting sociocultural values that can attach to the visualization and narration of data, to the relation of data to geographic visuality. For, the Creek Snakes might remind us, not all fatal maps are Western.

There may be ways to decouple our cartographic impulses from the feelings we get from the rapid technological and bureaucratic transformations we are experiencing, which are both inheritances from and resonances of those of Willard and Posey's world. If we are to continue to think by way of the metaphor of the map, one healthy path might be to regard deep mapping from a decolonial perspective. Post-custodial approaches to archival preservation and community protocol-based access policies for data offer provocative models for how to implement such perspectives practically. ${ }^{17}$ The creation of deep maps would thus not only be fundamentally a collaborative endeavor with communities represented in the map, but one

17. For a range of examples, see Christen 2012, 2870-93; Kelley and Francis 2005, 85-111; Heath, Kelleher, Sangwand, and Wood 2010, 165-78; and BoAdLe 2004, 242-52. 
whose protocols and products were created to enhance the activities those communities prioritize.

Sometimes even in the best of collaborations the communities involved cannot agree on priorities, and sometimes - perhaps often — with a decolonial approach no map, drawn, narrated, or otherwise, will result. Perhaps even, as in the case of sacred Navajo sand paintings, old designs must be erased. The academy has tended to take as its priority the creation of resources and narratives that are valuable precisely because they are not restricted by local priorities. Revelation may come at the cost of inducing conflict, the thinking goes, but in the name of truth, sometimes there must be conflict. But Indigenous thinkers, who often prioritize community cohesion and the generation of wisdom, and more recently the "post-critical" or "reparative" schools of cultural criticism, agree that this is a mode of work worth calling into question. And if the map is to be drawn from more than one perspective, then the ontology of each map's generation must be put to question, its necessity into doubt. The very attempt to make a deep map might then encourage connectedness across the different interests in a place, without merely creating what many maps in the Western tradition have been: a record of the failure of one group to relinquish real or imagined authority over another.

Water doesn't have to be deep for you to drown in it, and when you are drowning, a map can't help you. The historical banks of the river that took Posey's life are themselves drowned, in the waters of Lake Eufaula. Posey's Muscogee Nation maintains a Geospatial Department, whose projects include GIS mapping the allotments Posey helped to create. ${ }^{18}$ What does the ancient technique of deep mapping look like from Indian Country? What might Posey's work and fate offer to the emerging poetics and ethics of "immersive environments"? What would it mean to embrace the "silences" and "mysterious room" that Posey loved about the plains? Or to begin a mapping exercise by thinking about Willard's and Posey's relationships with water? It is not that indigenous epistemologies can "save" us or offer a "better" or more perfect version of the kinds of spatial histories we want to tell. It is rather that the process of creating deep maps or even thinking about what they can bring us might do more than just confront and embrace those epistemologies and their implications. That process can include people who have competing epistemological investments in deep

18. See Muscogee (Creek) Nation Geospatial Department: Geographic Information Systems, Projects page, http://mcngis.com/index.php/projects. 
mapping - people whose conceptions of mapping, of depth, and of history may carry us beyond the star-spangled scroll and the rocked cradle.

University of Nebraska, Lincoln

\section{Works Cited}

Basso, Keith H. 1996. Wisdom Sits in Places. Albuquerque: University of New Mexico Press.

Boadle, Dan. 2004. "Reinventing the Archive in a Virtual Environment: Australians and the Non-Custodial Management of Electronic Records", Australian Academic E Research Libraries 35.3: 242-52.

Bodenhamer, David J., John Corrigan, and Trevor M. Harris, eds. 2015. Deep Maps and Spatial Narratives. Bloomington: Indiana University Press.

Chapin, Mac, Bill Threlkeld, and Center for the Support of Native LANDs. 2001. Indigenous Landscapes: A Study in Ethnocartography. Arlington, VA: Center for the Support of Native Lands.

Christen, Kimberly. 2012. "Does Information Really Want to Be Free?: Indigenous Knowledge and the Politics of Open Access", International Journal of Communication 6: 2870-93.

Clare, Israel Smith. 1878. Illustrated Universal History. Philadelphia: J.C. McCurdy. Harjo, Joy. 2015. "Once the World Was Perfect”, In Conflict Resolution for Holy Beings. New York: W.W. Norton.

Heath, Fred, Christian Kelleher, T-Kay Sangwand, and Kevin Wood. 2010. "Confronting challenges of documentation in the digital world: the Human Rights Documentation Initiative at the University of Texas". In Transforming Research Libraries for the Global Knowledge Society, edited by Barbara Dewey, 165-78. Oxford: Chandos.

Indigenous Mapping Workshop. 2015. http://imwcanada2015.earthoutreach.org. Joyce, Barry. 2015. The First U.S. History Textbooks: Constructing and Disseminating the American Tale in the Nineteenth Century. Lanham, MD: Lexington Books.

Kelley, K. and H. Francis. 2005. "Traditional Navajo Maps and Wayfinding", American Indian Culture and Research Journal 29.2: 85-111.

Kitchin, Rob, Chris Perkins, and Martin Dodge. 2009. "Thinking about Maps”. In Rethinking Maps: New Frontiers in Cartographic Theory, edited by Martin Dodge, Rob Kitchin and Chris Perkins, 1-25. Routledge: London.

KLEIN, Lauren. 2014. "Feminist Data Visualization”, public lecture, HUMlab, Umeá University, Sweden, http://stream.humlab.umu.se/?streamName=feminist_data.

Lew is, G. Malcom, ed. 1998. Cartographic Encounters: Perspectives on Native American Mapmaking and Map Use. Chicago: University of Chicago Press.

Littrefield, Daniel F. 1992. Alex Posey: Creek Poet, Journalist, and Humorist. Lincoln: University of Nebraska Press. 
Lutz, Alma. 1929. Emma Willard, Daughter of Democracy. Boston: Houghton Mifflin Company.

Mundy, Barbara. 1996. The Mapping of New Spain: Indigenous Cartography and the Maps of the Relaciones Geográficas. Chicago: University of Chicago Press.

Muscogee (Creek) Nation Geospatial Department: Geographic Information Systems, Projects page, http://mcngis.com/index.php/projects. 2010-2019.

Pearce, Margaret Wickens and Renee Paulani Louis. 2008. "Mapping Indigenous Depth of Place", American Indian Culture and Research Journal 32.3: 107-26.

Posey, Alexander. 2008. Song of the Oktahutche: Collected Poems, edited by Matthew Wynn Sivils. Lincoln: University of Nebraska Press.

1993. The Fus Fixico Letters, edited by Daniel Littrefield, JR. and Carl A.

Petty Hunter. Lincoln: University of Nebraska Press.

- 1910. The Poems of Alexander Lawrence Posey, edited by Minnie Posey. Topeka, KS: Crane.

Ridge, Mia, Don LaFreniere, and Scott Nesbit. 2013. "Creating Deep Maps and Spatial Narratives through Design", International Journal of Humanities and Arts Computing 7.1-2: 176-89.

Ritterbush, Lauren W. et al. 2018. "Kanza Language and Landscape — The Kansas

River” @ https://tourbuilder.withgoogle.com/builder\#play/ahJzfmd3ZWItdG91cmJ1aWxkZXJyEQsSBFRvdXIYgICAoM78_QgM

Rundstrom, R. A. 1998. "Mapping, the White Man's Burden”, The Common Property Resource Digest 45: 1-9.

1991. "Mapping, Postmodernism, Indigenous People and the Changing Direction of North American Cartography", Cartographica 28.2: 1-12.

Schulten, Susan. 2012. Mapping the Nation: History and Cartography in NineteenthCentury America. Chicago: University of Chicago Press.

- 2007. "Emma Willard and the Graphic Foundations of American History", Journal of Historical Geography 33: 542-64

Sparke, Matthew. 1998. "A Map that Roared and an Original Atlas: Canada, Cartography, and the Narration of Nation", Annals of the Association of American Geographers 88.3: 463-95.

Stedman, Edmund Clarence. 1900. An American Anthology: 1787-1899. Boston: Houghton Mifflin.

The Ways @ https://theways.org/. Wisconsin Public Television Education. 2019.

Willard, Emma Hart. 1866. Abridged History of the United States, or Republic of America, new and enlarged edition. New York: A.S. Barnes.

-1847. An Appeal to the Public. New York: A.S. Barnes.

- 1845. Universal History in Perspective, second edition. New York: A.S. Barnes. 1829. History of the United States, or Republic of America: Exhibited in Connexion with its Chronology and Progressive Geography; by Means of a Series of Maps, etc. New York: White, Gallagher \& White. 
1819. An Address to the Public; Particularly to the Members of the Legislature of New-York, Proposing a Plan for Improving Female Education. Middlebury, VT. Printed by J. W. Copeland.

Wомаск, Craig. 1999. Red on Red: Native American Literary Separatism. Minneapolis: University of Minnesota Press. 